Serum Gamma-Glutamyltransferase and Intima-Media Thickness: Pointing Again to Wall/Lumen Interactions in Atherosclerosis

A. Pompella, M. Emdin, A. Paolicchi and M. Franzini

ANGIOLOGY 2011 62: 105

DOI: $10.1177 / 0003319710386474$

The online version of this article can be found at:

http://ang.sagepub.com/content/62/2/105

\author{
Published by: \\ (9)SAGE \\ http://www.sagepublications.com
}

Additional services and information for Angiology can be found at:

Email Alerts: http://ang.sagepub.com/cgi/alerts

Subscriptions: http://ang.sagepub.com/subscriptions

Reprints: http://www.sagepub.com/journalsReprints.nav

Permissions: http://www.sagepub.com/journalsPermissions.nav

Citations: http://ang.sagepub.com/content/62/2/105.refs.html 


\title{
Serum Gamma-Glutamyltransferase and Intima-Media Thickness: Pointing Again to Wall/Lumen Interactions in Atherosclerosis
}

\author{
Pompella A, MD, PhD', Emdin M, MD, PhD², Paolicchi A, MD, PhD', and Franzini M, $\mathrm{PhD}^{3}$
}

Over the last decade, several epidemiology studies - including the Framingham Heart Study ${ }^{1}$ - have documented the independent value of serum gamma-glutamyltransferase (GGT) activity in the prognostic evaluation of cardiovascular diseases. It was observed that GGT activity is associated with overall mortality and cardiovascular events, either in unselected populations or in patients with established coronary artery disease, independently from potential confounders such as liver disease and alcohol abuse.

Eroglu et al, ${ }^{2}$ in this issue of Angiology, provide an important confirmation, insofar as they report a significant correlation between serum GGT activity and another primary atherosclerosis marker, the carotid intima-media thickness. These observations once more point to a potential connection between circulating GGT activity and the diseased arterial wall. GGT activity has been shown to participate in cellular and extracellular redox equilibria, being able to produce both antioxidant as well as prooxidant effects depending on interactions with metal ions. ${ }^{3}$ Histochemical observations have suggested the possibility that GGT activity may actually play a direct role in the pathogenesis of atherosclerosis and its complications. GGT activity accumulates in intimal layers of atherosclerotic plaques, ${ }^{4,5}$ where its participation by redox effects in redox-sensitive processes in the progression of lesions-chemotaxis and inflammation, proliferation of myofibroblasts, protease/antiprotease balance - can be envisaged. ${ }^{6}$ However, additional studies are required to clarify the exact origins and dynamics of serum GGT levels. The circulating enzyme is thought to be mainly released from the liver and constitutively high serum GGT has been reported in families as an inherited autosomal dominant characteristic. ${ }^{7}$ However, the importance of genetic factors is still a matter of debate, and the current view is that a mixture of genetic and environmental factors may influence serum levels of GGT. ${ }^{7}$ It has even been suggested that increased serum GGT activity may represent a link between atherosclerosis and exposure to environmental pollutants. ${ }^{8}$ According to another view, a source of serum GGT might be platelets: it was thus proposed that the increased GGT activity observed in patients with atherosclerosis may originate from increased platelet aggregation at the site of plaques. ${ }^{9,10}$

In their present study, Eroglu et $\mathrm{al}^{2}$ discuss the possibility that circulating GGT in patients with atherosclerosis may derive from the vascular lesions, where GGT accumulates. The alternative hypothesis, that GGT found in plaques may derive from the circulating enzyme, is also conceivable and has recently found some confirmation in studies aiming to compare the biochemical characteristics of GGT from the 2 sources. ${ }^{11}$ Indeed, a recently proposed novel analytical approach allows to separate serum GGT into 4 distinct chromatographic fractions, of which 3 represent aggregates of GGT with other presently unknown proteins. ${ }^{12}$ In healthy participants, the major cardiovascular risk factors are associated with the high molecular weight GGT fraction termed "b-GGT," which is the only fraction detectable in plaques. ${ }^{13}$

Future studies will further elucidate the nature of these protein complexes and their respective significance in the pathogenesis of atherosclerosis. Also, the relationship between serum GGT and C-reactive protein and fasting glucose, ${ }^{14}$ as well as other vascular diseases such as aortic valve stenosis, needs to be investigated. ${ }^{15}$

\section{Declaration of Conflicting Interests}

The author(s) declared no conflicts of interest with respect to the authorship and/or publication of this article.

\section{Funding}

The financial support by the University of Pisa is gratefully acknowledged.

\footnotetext{
'Department of Experimental Pathology, University of Pisa Medical School, Pisa, Italy

${ }^{2}$ Department of Cardiovascular Medicine, G Monasterio Foundation, CNR-Regione Toscana, Pisa, Italy

${ }^{3}$ Scuola Superiore S. Anna, Pisa, Italy

Corresponding Author:

Maria Franzini, Scuola Superiore S. Anna, Pisa, Italy

Email: franzini@biomed.unipi.it
} 


\section{References}

1. Lee DS, Evans JC, Robins SJ, et al. Gamma glutamyl transferase and metabolic syndrome, cardiovascular disease, and mortality risk: the Framingham Heart Study. Arterioscler Thromb Vasc Biol. 2007:27(1):127-133.

2. Eroglu S, Sade LE, Polat E, Bozbas H, Ulus T, Muderrisoglu H. Association between serum gamma-glutamyl transferase activity and carotid intima media thickness. Angiology, IN PRESS.

3. Paolicchi A, Dominici S, Pieri L, Maellaro E, Pompella A. Glutathione catabolism as a signalling mechanism. Biochem Pharmacol. 2002;64(5-6): 1029-1037.

4. Paolicchi A, Minotti G, Tonarelli P, et al. Gamma-glutamyl transpeptidase-dependent iron reduction and low density lipoprotein oxidation-a potential mechanism in atherosclerosis. J Invest Med. 1999;47(3):151-160.

5. Paolicchi A, Emdin E, Ghliozeni E, et al. Atherosclerotic plaques contain gamma-glutamyl transpeptidase activity. Circulation. 2004;109:1440.

6. Emdin M, Pompella A, Paolicchi A. Gamma-glutamyltransferase, atherosclerosis, and cardiovascular disease: triggering oxidative stress within the plaque. Circulation. 2005;112(14):2078-2080.

7. Whitfield JB, Zhu G, Nestler JE, Heath AC, Martin NG. Genetic covariation between serum gamma-glutamyltransferase activity and cardiovascular risk factors. Clin Chem. 2002;48(9):1426-1431.

8. Pompella A, Emdin M, Franzini M, Paolicchi A. Serum gammaglutamyltransferase: linking together environmental pollution, redox equilibria and progression of atherosclerosis? Clin Chem Lab Med. 2009;47(12):1583-1584.

9. Krijgsman B, Hamilton G, Mikhailidis DP. Gammaglutamyltransferase and vascular disease. Clin Chem. 2003; 49(3):522-523.

10. Pompella A, Paolicchi A, Emdin M, Mikhailidis DP. Platelet activation, gamma-glutamyltransferase and stent restenosis-Comment on the article by Ulus et al. Atherosclerosis. 2007;195(1): e231-e232.

11. Franzini M, Corti A, Martinelli B, et al. Gammaglutamyltransferase activity in human atherosclerotic plaques-biochemical similarities with the circulating enzyme. Atherosclerosis. 2009;202(1):119-127.

12. Franzini M, Ottaviano V, Fierabracci V, et al. Fractions of plasma gamma-glutamyltransferase in healthy individuals: reference values. Clin Chim Acta. 2008;395(1-2):188-189.

13. Franzini M, Paolicchi A, Fornaciari I, et al. Cardiovascular risk factors and gamma-glutamyltransferase fractions in healthy individuals. Clin Chem Lab Med. 2010;48(5):713-717.

14. Emdin M, Passino C, Michelassi C, Donato L, Pompella A, Paolicchi A. Additive prognostic value of gamma-glutamyltransferase in coronary artery disease. Int J Cardiol. 2009;136(1):80-85.

15. Cappelli S, Epistolato MC, Vianello AM, et al. Aortic valve disease and gamma-glutamyltransferase: accumulation in tissue and relationships with calcific degeneration. Atherosclerosis. 2010; IN PRESS. 